\title{
Sizing Optimization of Hybrid Photovoltaic-wind-battery System towards Zero Energy Building using Genetic Algorithm
}

\author{
Farhana Johar, Julies Bong Shu Ai and Fuaada Mohd Siam \\ Department of Mathematical Sciences \\ Faculty of Sciences, Universiti Teknologi Malaysia \\ 81310 UTM Johor Bahru, Malaysia \\ *Corresponding author: farhanajohar@utm.my
}

Article history

Received: 27 August 2019

Received in revised form: 16 November 2020

Accepted: 17 November 2019

Published online: 1 December 2020

\begin{abstract}
A new topic of Zero Energy Building (ZEB) is getting famous in research area because of its goal of reaching zero carbon emission and low building cost. Renewable energy system is one of the ideas to achieve the objective of ZEB. Genetic Algorithm (GA) is widely used in many research areas due to its capability to escape from a local minimal to obtain a better solution. In our study, GA is chosen in sizing optimization of the number of photovoltaic, wind turbine and battery of a hybrid photovoltaic-wind-battery system. The aim is to minimize the total annual cost (TAC) of the hybrid energy system towards the low cost concept of ZEB. Two GA parameters, which are generation number and population size, have been analysed and optimized in order to meet the minimum TAC. The results show that the GA is efficient in minimizing cost function of a hybrid photovoltaic-wind-battery system with its robustness property.
\end{abstract}

Keywords Zero Energy Building (ZEB); Genetic Algorithm (GA); hybrid energy system; generation number; population size.

Mathematics Subject Classification 90B99, 90C27.

\section{Introduction}

In our daily life, energy is the main supply to many operations like printing, dwelling, cutting, computing, air conditioning and many others. Total energy demand of residence is increasing and one of the reasons of this increment is the expanding of population size. In Malaysia, the energy consumption has increased continuously at the rate of 6.62 percent from 1980 to 2012 as provided by Chong et al. [1]. However, not all of the generated energy is fully utilized although the energy demand is high. This excess energy results a energy wastage in the form of heat which will be released to the environment. Consequently, the problem of global warming arises if the generated energy is not fully utilized in daily operation. 
The temperature of global land and ocean surface temperature are increasing from 0.65 degree Celsius to 1.06 degree Celsius over the period of 1880 to 2012 [2]. Due to the reasons of increasing in energy demand, losses of energy and global warming, the concept of Zero Energy Building(ZEB) is slowly being implemented in new construction building. When there is high demand of energy, more and more energy need to be produced to supply the energy load.

During the process of energy transportation, energy is lost to the environment as heat energy. Besides, losses of energy might occur when the energy storage system undergoes charging and discharging process. Consequently, the total cost of a building is increasing when the rate of heat loss is high. There are two reasons of this heat loss problem, which is low efficiency of energy storage system for on-site energy source and high purchase cost for off-site energy source. Without a good management in constructing a building, the investors might face the problem of high carbon emission and high construction cost.

According to the fluctuating nature of solar and wind energies, photovoltaic and wind turbine hybrid systems needs an energy storage. This storage system, i.e. deep-cycle lead acid batteries will supply the remaining demand once the renewable sources is at the low level of energy.

Many studies are being carried out to apply the concept of zero energy for new building design although this concept is still considered as a new idea in most country. Basically the concept of ZEB is related to source of energy, type of energy source, carbon emission and investment cost. A study of Torcellini et al. [3] has summarized the concept of ZEB into four different categories. These four categories are site ZEB, source ZEB, emission ZEB and the last classification, which also the most important class of ZEB is cost ZEB. Recently, United States has set a goal of 50 percent of commercial buildings to become zero energy buildings by 2040 and for all commercial buildings by 2050 [4]. In Europe, the government also set a target that after 2020, all of the buildings in Europe must be built under the concept of ZEB [5]. The details about the concept of ZEB will be discussed in the following chapter with some literature reviews.

\section{Background of Zero Energy Building and Hybrid Energy System}

The concept of ZEB is about the idea of renewable energy system under the objectives of economical and environmental friendly. According to the study of Hernandez and Kenny [6], the authors provided a model of achieving an equilibrium level in between the generated energy from renewable energy system and energy usage of the building which resulted a healthier environment. Besides, Huat and Akasah [7] designed a ZEB with maximum daylighting and minimum thermal impact. This optimization of day lighting and thermal impact of photovoltaic provided a high energy efficiency of the building.

Moreover, climate condition is also one of the main factors in ZEB. In the study of Thalfeldt et al. [8], energy system and building are designed under the consideration of cold climate to achieve the concept of ZEB. However, an optimization of investment cost is not included in the study of Hernandez and Kenny [6], Huat and Akasah [7] and Thalfeldt et al. [8]. As stated by Pikas et al. [9] and Maleki and Pourfayaz [10], a high energy efficiency and cost optimality of photovoltaic are the key factors in achieving ZEB. These studies are mainly focused on one type of renewable energy system only which is photovoltaic. There exits problem of shortage of energy supply when the climate condition is cloudy. Therefore, our study chose a hybrid 
photovoltaic-wind-battery system as studied by Maleki and Pourfayaz [10] because the result showed that an optimum sizing of the hybrid photovoltaic-wind-battery system can be achieved in low cost.

However, there is increasing number of recent studies using Genetic Algorithm in sizing optimization of hybrid energy system with multiple variables as stated in review paper [11-12]. Studies done by Anoune et al. [13], Gan et al. [14] and Starke et al. [15] are able to obtain an optimum configuration of energy system in PV/ wind/ split-diesel/ battery hybrid energy system, hybrid wind-diesel-battery system and hybrid CSP-PV respectively. Hence, Genetic Algorithm is chosen in our study in sizing optimization the model of hybrid photovoltaic-windbattery system of the study of Maleki and Pourfayaz [10] towards the target of cost ZEB.

\section{Building Energy System Model}

There are many types of energy being used or being generated in our daily life such as electrical, mechanical, heat energy, wave energy and light energy. A good optimal control of energy system in a building is important to avoid energy loses and maximize utilization of energy corresponding to the energy demand of the building in order to achieve the target of cost ZEB. In this section, a literature on building design models are desired to review and classify into subsection of renewable energy systems which are photovoltaic system, wind turbine system and hybrid photovoltaic-wind-battery storage system. These three components of energy system have significant effects to the application of ZEB in different combination. The most efficient group of energy system can be determined by its total investment cost.

\subsection{Zero Energy Building Design Model}

Recently, many studies were done on reducing energy consumption and minimizing energy cost towards the target of ZEB. A study done by Pikas et al. [9] focused on saving energy usage and the result showed that energy saving can be achieved by maximizing the use of electricity within a building. However, it is challenging to save energy in current buildings design so the existing buildings might need to be renovated to ZEB since cost saving can be achieved under the concept of ZEB. Therefore, Pikas et al. [16] carried out another study on building renovation. The result showed that the pay back from an investment after renovation is approximately 20 years. The renovation cost is very high due to other aspects of renovation fees such as construction workers fee, existing workers allocation and penalty fee of delayed projects.

Therefore, a new building is recommended to be built under the concept of ZEB to prevent unnecessary renovation cost in future. By referring to the review of Lu et al. [17], a building design of ZEB can be summarized into passive design strategies, energy efficiency technologies and energy generation technologies. The design optimization of ZEB is depending on many factors because the effectiveness of a building design changes with climate condition and depends on geographical region on where the building allocation is.

For example, Kolokotsa et al. [18] used a simplified physical simulation model on climate change data, geometries, building physics, heating-ventilation-air-conditioning system, energygeneration system, natural ventilation, user behavior and thermal control towards the objectives of ZEB. The results showed that a simple model is cost efficient than a complex model. 
Therefore, a good selection of mathematical model of the renewable energy systems is important and will be discussed in the following section.

\subsection{Photovoltaic System}

Photovoltaic (PV) system is referring to a type of electric current generated by solar radiation from a solar panel. The ordinary notation of PV is solar PV power system or PV system [19]. From the study of Yang et al. [20], a simplified PV model is used where five parameters (photocurrent factor, temperature-voltage effect factor, dimension coefficient, series resistance and ideality factor at a maximum power point) are taken into consideration under the usual operating condition. These parameters are used to evaluate the performance of PV system. Generally, the percentage of solar radiation is also influenced by climate change and the structure of the solar panels because the environmental factors are uncontrollable. Hence, the uncertainties of weather condition are not considered in our study.

In contrast, Kaabeche et al. [21] focused on PV power generator only where the PV power generator is dependent on the area of a solar panel plane and its solar radiation on tilted surface as well as the PV generator efficiency. However, the performance of a PV model is greatly influence by its temperature. When the temperature of the PV module is increased, the power generated by a PV module decreases. Therefore, impact of temperature is included in the PV model of Li et al. [22] and varied from its ideal value during hot climate season. As we can observe from Yang et al. [20], Kaabeche et al. [21], Li et al. [22] and Wang et al. [23], solar radiation and temperature of a solar panel are the important factors which need to be included in a PV model. In the study of Ismail et al. [24] and Maleki and Pourfayaz [10], both of the authors applied a simplified PV model which included solar radiation, temperature coefficient and the normal operating cell temperature. The results showed that the PV output power contributed almost 90 percent of the energy demand due to a high performance of the PV model and a low unit PV cost. Thus, the simplified PV model is selected in our study and illustrated in the following equation (1).

$$
\rho_{p v}(t)=P_{R, P V} *\left(R / R_{r e f}\right) *\left[1+N_{T}\left(T_{c}-T_{r e f}\right)\right]
$$

where,

$$
\begin{aligned}
& \rho_{p v}(t)=\text { power generated by each } \mathrm{PV} \text { at time } t \\
& p_{R, P V}=\mathrm{PV} \text { rated power } \\
& R=\text { solar radiation } \\
& R_{r e f}=\text { solar radiation at reference conditions } \\
& N_{t}=\text { temperature coefficient of the } \mathrm{PV} \\
& T_{c}=\text { cell temperature } \\
& T_{r e f}=\text { cell temperature at reference conditions }
\end{aligned}
$$

Some of the parameters values like the solar radiation, is set as $1,000\left(\mathrm{~W} / \mathrm{m}^{2}\right)$, the cell temperature at reference conditions, $T_{\text {ref }}$ is set as $25^{\circ} \mathrm{C}$ and the temperature coefficient of the $\mathrm{PV}, N_{T}$ is $-3.7 \times 10^{-3}\left(1{ }^{\circ}\right)$ for mono and polycrystalline silicon ([24] and [10]). Lastly, the parameter cell temperature, is calculated using equation (2).

$$
T_{c}=T_{a i r}+\left(\frac{N O C T-20}{800}\right) * R
$$


where,

$$
\begin{aligned}
& T_{\text {air }}=\text { the ambient air temperature } \\
& \text { NOCT }=\text { the normal operating cell temperature in }{ }^{\circ} \mathrm{C}
\end{aligned}
$$

These two temperature values can be obtained from solar panel manufacturer and declared by them in the product module. Consequently, the total power generated by PV system can be computed by using mathematical equation (3).

$$
P_{P V}(t)=N_{P V} \times \rho_{\rho v}(t)
$$

where,

$$
\begin{aligned}
& P_{P V}(t)=\text { the overall produced power by } \mathrm{PV} \text { system } \\
& N_{P V}=\text { the number of } \mathrm{PV} \text { system }
\end{aligned}
$$

\subsection{Wind Turbine System}

Energy produced by wind turbine is depending on wind speed condition as well as the height of a power towel because deviation of wind speed corresponds to the height of power tower. Yang et al. [20], Kaabeche et al. [21], Li et al. [22], Wang et al. [23] and Maleki and Pourfayaz [10] studied the wind turbine system model under three important factors which are power output curve, wind speed distribution of the allocated wind turbine as well as the power tower height. Thus, a general wind energy conversion system is dependent on the wind speed distribution and its power generation efficiency which is:

$$
\rho W T(t)=\left\{\begin{array}{ccc}
0 & , & V(t)<V_{I N} \\
a((t))^{3}-b P_{R} & , & V_{I N}<V(t)<V_{R} \\
P_{R} & , & V_{R}<V(t)<V_{U P} \\
0 & , & V(t)<V_{U P}
\end{array}\right.
$$

where

$$
\begin{aligned}
\rho W T(t) & =\text { Power produced by a wind turbine at time } t \\
V(t) & =\text { The wind speed at time } t \\
V_{I N} & =\text { The low cut speed, } \\
V_{U P} & =\text { The up cut speed, } \\
V_{R} & =\text { The speed related to nominal power. }
\end{aligned}
$$

Nevertheless, the parameters $a$ and $b$ can be calculated from equation (5):

$$
\begin{aligned}
& a=P_{R, W T} /\left(V_{R}^{3}-V_{I N}^{3}\right) \\
& b=V_{I N}^{3} /\left(V_{R}^{3}-V_{I N}^{3}\right)
\end{aligned}
$$

where $P_{R, W T}$ is the nominal power of wind turbine.

The overall wind turbine energy output system can be illustrated as:

$$
P_{W T}(t)=N_{W T} \times \rho W T(t),
$$

where,

$P_{W T}(t)=$ The overall produced power by wind turbine system

$N_{W T}=$ The number of wind turbines 


\subsection{Hybrid PV-Wind Turbine System}

An individual PV or wind turbine system application can reduce the energy cost expenses of a building. However, Yang et al. [20] stated that a hybrid system of PV-wind turbine proposed a lower cost than the individual renewable energy system. Moreover, Kaabeche et al. [21] also introduced a hybrid energy generator system of PV array and wind turbine that satisfied the load demand according to the system reliability requirements. This is because a reliable hybrid system is an optimum system configuration in reducing the investment cost. A hybrid solarwind system where the wind turbine is built besides the building and solar panels are built on the building surface while batteries, DC and AC inverters are allocated inside the building. Then the building can generate renewable energy on site. The excess energy generated by PV module and wind turbine will be used to charge the battery and discharge to supply the load demand.

\subsection{Battery Bank Model}

When there is excess of energy produced by PV and wind turbine system during summer season or high wind speed weather, battery is used to store surplus energy (under charging status). Similarly, the battery will supply energy to the load demand when there is less wind or solar radiation (under discharging status). The charging and discharging process in a battery can be derived as state of charge of the battery. Therefore, in order to optimize the utilization of the generated energy towards the goal of ZEB and minimize the investment cost of renewable energy as well as reduce the carbon dioxide emission, a good battery bank model is needed as a storage system.

Normally, the battery charging and discharging efficiencies are difficult to be calculated and these values are set to 1 [20]. However, this is not accurate since energy availability from PV and wind turbine systems are not consistent. This is because the battery will undergo charging and discharging status inconsistently due to uncontrollable weather condition. Therefore, the energy system model used by Kaabeche et al. [21], Askarzadeh [25], Maleki and Askarzadeh [26] and Maleki and Pourfayaz [10] focused on the state of charge of a battery where the unit of state of charge are percentage points. The inverse of state of charge is called depth of discharge. Depth of discharge is another alternative way to describe the state of charge of a battery where state of charge is not necessarily proportional to depth of discharge. In study of Maleki and Pourfayaz [10], the depth of charge of battery is set as 0.8 . This can be explained as a battery with 100-unit power but only 80-unit power can be transferred to support the load demand. Although there are many other factors that will affect the performance of a battery, however state of charge is the main concern as shown in equation (7) [10].

$$
E_{\text {Batt }}(t)=E_{\text {Batt }}(t-1) *(1-\sigma)+\left[\left(E_{P V}(t) * \eta_{\text {Inv }}+E_{W T}(t) * \eta_{\text {Inv }}^{2}\right)-\frac{E_{\text {Load }}(t)}{\eta_{\text {Inv }}}\right] * \eta_{\text {Batt }},
$$

where

$$
\begin{array}{cl}
E_{\text {Batt }}(t) & =\text { The charge quantities of battery bank at time } t \\
E_{\text {Batt }}(t-1) & =\text { The charge quantities of battery bank at time } t-1 \\
\sigma & =\text { The hourly self-discharge rate } \\
\eta_{\text {Inv }} & =\text { The invertor efficiency } \\
\eta_{\text {Batt }} & =\text { The discharge efficiency of the battery bank } \\
E_{\text {Load }} & =\text { The load demands } \\
E_{W T} & =\text { Total output of PV } \\
E_{P V} & =\text { Total output of wind generators }
\end{array}
$$


Since $\eta_{\text {Batt }}$ is assumed to be 1 , the mathematical battery model can be simplified to

$$
E_{\text {Batt }}(t)=E_{\text {Batt }}(t-1) *(1-\sigma)+\left[\left(E_{P V}(t) * \eta_{\text {Inv }}+E_{W T}(t) * \eta_{\text {Inv }}^{2}\right)-\frac{E_{\text {Load }}(t)}{\eta_{\text {Inv }}}\right]
$$

and the values of $\eta_{I n v}$ and $\sigma$ are set to 95 percent and 0.0002 respectively.

\section{Objective Function}

An optimum design configuration of a ZEB is not only depending on the optimal energy system but also influence by the performance of cost optimality. It is important to consider the cost when designing a building and a review on the cost optimality towards the target of ZEB will be carried out in this section.

Based on the study of Kapsalaki et al. [27], the researchers concerned on lowest life cycle cost and the investment payback period methods where the cost is corresponding to the initial cost. In another words, the total investment cost to design a building is high if the initial cost is high such as expensive energy system and building envelope. Due to the reason of high initial of investment, a good budget planning is needed to prevent timeless capital feedback. In another study by Pikas et al. [9], the author stated that all the present values of cash outflow are needed to connect with a period of 20 years such as the cost of windows, wall and solar PV. The author found that reduce energy consumption of a building is the only way to minimize the net present value because of lower construction fees on lesser PV are needed. These two studies have brought up an important message, i.e, to achieve a lower investment cost, estimated capital cost as well as total annualized costs of a new building construction project has to be minimized.

Since the uncertainty of weather and climate condition will cause a shortage of energy supply, a comparison cost of PV system, wind turbine energy system and a hybrid renewable energy system was done by many researchers in order to acquire a best energy system performance regarding its total costs. In study of Li et al. [22] and Maleki and Pourfayaz [10], the author compared the total cost of PV-battery system, wind turbine-battery system and a hybrid of $\mathrm{PV}$-wind-battery system. The outcome indicated a hybrid PV-wind-battery system is more cost-effective than an individual PV-battery or wind turbine-battery system.

Consequently, the objective function of our study will focus on total annual capital cost and annual maintenance cost which is called total annual cost (TAC) of a building as stated in equation (9) below. Capital cost occurs at the beginning of a project while maintenance cost occurs during the project life.

$$
\text { minimize } T A C=C_{C p t}+C_{M t n}
$$

where,

$$
\begin{aligned}
C_{C p t} & =\text { The total annual capital cost } \\
C_{M t n} & =\text { The total annual maintenance cost }
\end{aligned}
$$

By referring to study of Maleki and Pourfayaz [10], the lifespan of each battery in the $\mathrm{PV} /$ wind/battery system is assumed to be 5 years and represented by the following equation.

$$
C_{\text {Batt }}=P_{\text {Batt }} \times\left(1+\frac{1}{(1+i)^{5}}+\frac{1}{(1+i)^{10}}+\frac{1}{(1+i)^{15}}\right),
$$


where

$$
\begin{aligned}
C_{\text {Batt }} & =\text { The present worth of battery } \\
P_{\text {Batt }} & =\text { The battery prices } \\
i & =\text { Annual interest rate }
\end{aligned}
$$

The total annual capital costs and maintenance costs are provided in equations (11) and (12) respectively $([28],[10])$.

$$
C_{C p t}=\frac{i(1+i)^{n}}{(1+i)^{n}-1}\left[N_{W i n d} \times C_{W i n d}+N_{P V} \times C_{P V}+N_{B a t t} \times C_{B a t t}\right],
$$

where

$$
\begin{aligned}
N_{W i n d} & =\text { The number of wind turbine } \\
C_{W i n d} & =\text { Unit cost of wind turbine } \\
N_{P V} & =\text { The number of PV } \\
C_{P V} & =\text { Unit cost of PV } \\
N_{\text {Batt }} & =\text { The number of battery } \\
C_{B a t t} & =\text { Unit cost of battery } \\
C_{M t n} & =N_{P V} \times C_{M t n}^{P V}+N_{W i n d} \times C_{M t n}^{\text {Wind }},
\end{aligned}
$$

where

$$
\begin{aligned}
& C_{\text {Mtn }}^{P V}=\text { the annual maintenance costs of PV } \\
& C_{\text {Mtn }}^{\text {wind }}=\text { the annual maintenance costs of wind turbine }
\end{aligned}
$$

Similar to other optimization method, some constraints are needed to be satisfied which are the number of wind turbine, PV and battery. The maximum number of PV, wind turbine and batteries are 200, 200 and 20000 respectively [26].

$$
\begin{gathered}
N_{P V}=\text { Integer }, \quad 0 \leq N_{P V} \leq N_{P V}^{\max } \\
N_{W i n d}=\text { Integer }, \quad 0 \leq N_{W i n d} \leq N_{W \text { maxd }}^{\text {inax }} \\
N_{\text {Batt }}=\text { Integer }, \quad 0 \leq N_{\text {Batt }} \leq N_{\text {Batt }}^{\text {max }}
\end{gathered}
$$

where,

$$
\begin{aligned}
N_{P V}^{\max } & =\text { The maximum available number of } \mathrm{PV} \\
N_{W \text { ind }}^{\max } & =\text { The maximum available number of wind turbines } \\
N_{B \text { max }}^{\text {max }} & =\text { The maximum available number of batteries }
\end{aligned}
$$

These constraints are modified into a shorter range to reduce the search space and computing time. This modification is made according to the summary results obtained by different algorithms in Maleki and Pourfayaz [10] with a minimum two percent loss of power supply probability. Thereafter, the modified number range of wind turbine, PV and battery are as follows.

$$
\begin{aligned}
144 & \leq N_{P V} \leq 165 \\
0 & \leq N_{\text {Wind }} \leq 9 \\
1529 & \leq N_{\text {Batt }} \leq 3221
\end{aligned}
$$




\section{Genetic Algorithm}

The basic arithmetic of GA consists of generation, population number, mutation and crossover operator [29]. Firstly, the population number is a number of possible solutions of the model which will be evaluated corresponding to the objective function and this is called a fitness evaluation process. Then the process proceeds with elimination and selection process for example eliminating poor solution while keeping the better solutions. Lastly, these selected solutions will be carried forward to the next generation until a stopping criterion is met. The stopping criterion can be maximum computing time or maximum number of generations. A general pseudo-code of GA based on the roulette wheel selection is shown as follows [30].

Begin

Initialize the population, $\mathrm{P}$ with random number.

Evaluate each individual in $\mathrm{P}$ and sort $\mathrm{P}$ according to the fitness value. Repeat

Select individual for reproduction and apply crossover operator.

Evaluate offspring.

Select individual for reproduction and apply mutation operator.

Evaluate offspring.

Select individuals to the next generation.

if

Individual is better than worst individual in $\mathrm{P}$ then remove worst individual from $\mathrm{P}$.

else

Repeat

Until stopping criteria is met.

End

\section{Results and Analysis}

In this section, all the computational results will be analyzed and discussed. All of the computation calculation are performed using a laptop of Intel(R) Core(TM) i5 CPU, M 460 @ 2.53GHz, $4.00 \mathrm{~GB}$, Window 7, 64-bit operating system and Microsoft Visual C++ Studio 2010 Professional. Firstly, analysis will focus on different setting of genetic parameters to identify the most optimize genetic parameters on minimizing TAC of hybrid PV-wind-battery system. Continuously, the best sizing of PV, wind turbine and battery will be list out corresponding to its minimum TAC. Finally, the performance of GA in our study will be concluded at the end of this paper.

\subsection{Identify the Best Generation Number under Constant Population Size}

In this section, the generation number is optimized to prevent premature convergence and infinite iteration. Based on the experimental results, different population size produced the different best generation number. A summary can be made to form a range of the best generation number corresponding to different population size as shown in Table 1. Apart from 2,000 population size, the setting of maximum generation number must not less than 32,000 but at least 78,000 to ensure the algorithm converges to a good and nearly optimum solution. 
Table 1: The Best and Minimum Generation Number in GA

\begin{tabular}{|l|l|l|l|l|l|l|}
\hline $\begin{array}{c}\text { Population } \\
\text { Size }\end{array}$ & $\begin{array}{c}\text { Number } \\
\text { of PV } \\
\left(N_{P V}\right)\end{array}$ & $\begin{array}{c}\text { Number } \\
\text { of Wind } \\
\text { Turbine } \\
\left(N_{\text {Wind }}\right)\end{array}$ & $\begin{array}{c}\text { Number } \\
\text { of Battery } \\
\left(N_{\text {Batt }}\right)\end{array}$ & $\begin{array}{c}\text { Average } \\
\text { TAC }\end{array}$ & $\begin{array}{c}\text { The Best } \\
\text { Generation } \\
\text { Number }\end{array}$ & $\begin{array}{c}\text { Minimum } \\
\text { Generation } \\
\text { Number in } \\
\text { GA }\end{array}$ \\
\hline 100 & 148 & 3 & 1,571 & $5,5407.26$ & 44,248 & 45,000 \\
\hline 2,000 & 158 & 2 & 1,586 & $56,023.36$ & 1,441 & 2,000 \\
\hline 4,000 & 154 & 5 & 1,560 & $58,080.14$ & 77,284 & 78,000 \\
\hline 6,000 & 156 & 1 & 1,581 & $55,511.14$ & 31,991 & 32,000 \\
\hline 8,000 & 157 & 1 & 1,621 & $56,914.02$ & 38,587 & 39,000 \\
\hline
\end{tabular}

Since the largest generation number is 77,284 among the five computation experiments thus, a minimum generation number of 78,000 must be set in the algorithm. All the experiments above will be able to reach a better solution provided the minimum generation number is 78,000 regardless of the population size. From this simulation, the best generation number is 77,284 and the best number of PV, wind turbine and battery are 154, 5 and 1,560, respectively. However, an appropriate population size can increase the efficiency of GA as the outcome might be a poor solution when the population is large. Hence, a few experiments have been carried out to identify the best population size in the following section.

\subsection{Identify the Best Population Size under Constant Generation Number}

Four different simulations at constant generation number of 100, 1,000, 10,000 and 100,000 at various population size are carried out in this section to determine the best population size by comparing the minimum values of objective function. The best population size as well as the computing time will be summarized at the end of this paper.

In summary, the best population size of GA is dependent on the number of generation. Table 2 and Table 3 show the results of best population size obtained by setting the different minimum and maximum generation number, respectively. It can be seen clearly that the solution obtained by setting the minimum generation number are producing the good solution compared with setting by the maximum generation number.

This indicates that minimum and the maximum points are the key factor that must be taken into consideration in choosing the best population size. These results are shown in Table 2 and Table 3 below with an additional information of computing time in seconds.

For 100 generation, there is a possibility of obtaining a bad solution if the range of population size is set in between 100 to 4,500 since population size of 4,200 returned the result to a very high average TAC value at population size of 4,200, shown in Table 3. Whereas in 1,000 and 10,000 generation, the experiments returned a maximal at population number of 6,100 and 6,200 . In this case, a large value of population number which is greater than 6,000 will lead the search to a poor outcome. 
Table 2: Summary of the Results of Minimal at 100, 1000, 10000 and 100,000 Times of Generation

\begin{tabular}{|l|l|l|l|l|l|l|}
\hline $\begin{array}{c}\text { Generation } \\
\text { Number }\end{array}$ & $\begin{array}{c}\text { Number } \\
\text { of PV } \\
\left(N_{P V}\right)\end{array}$ & $\begin{array}{c}\text { Number } \\
\text { of Wind } \\
\text { Turbine } \\
\left(N_{\text {Wind }}\right)\end{array}$ & $\begin{array}{c}\text { Number } \\
\text { of Battery } \\
\left(N_{\text {Batt }}\right)\end{array}$ & $\begin{array}{c}\text { The Best } \\
\text { Population } \\
\text { Size }\end{array}$ & $\begin{array}{c}\text { Average } \\
\text { TAC }\end{array}$ & $\begin{array}{c}\text { Computing } \\
\text { Time } \\
\text { (second) }\end{array}$ \\
\hline 100 & 150 & 2 & 1,617 & 6,600 & $54,742.18$ & 10 \\
\hline 1,000 & 150 & 0 & 1,557 & 2,300 & $54,187.58$ & 16 \\
\hline 10,000 & 303 & 0 & 1,555 & 4,000 & $54,143.20$ & 431 \\
\hline 100,000 & 144 & 0 & 1,529 & 3,000 & $5,3031.32$ & 2,352 \\
\hline
\end{tabular}

Table 3: Summary of the Results of Maximal at 100, 1000, 10000 and 100000 Times of Generation

\begin{tabular}{|l|l|l|l|l|l|l|}
\hline $\begin{array}{c}\text { Generation } \\
\text { Number }\end{array}$ & $\begin{array}{c}\text { Number } \\
\text { of PV } \\
\left(N_{P V}\right)\end{array}$ & $\begin{array}{c}\text { Number } \\
\text { of Wind } \\
\text { Turbine } \\
\left(N_{\text {Wind }}\right)\end{array}$ & $\begin{array}{c}\text { Number } \\
\text { of Battery } \\
\left(N_{\text {Batt }}\right)\end{array}$ & $\begin{array}{c}\text { The Best } \\
\text { Population } \\
\text { Size }\end{array}$ & $\begin{array}{c}\text { Average } \\
\text { TAC }\end{array}$ & $\begin{array}{c}\text { Computing } \\
\text { Time } \\
\text { (second) }\end{array}$ \\
\hline 100 & 150 & 1 & 2,198 & 4,200 & $73,823.22$ & 5 \\
\hline 1,000 & 156 & 2 & 1,625 & 6,100 & $57,277.98$ & 88 \\
\hline 10,000 & 296 & 1 & 1,662 & 6,200 & $57,448.46$ & 931 \\
\hline 100,000 & 146 & 0 & 1,534 & 2,100 & $53,256.42$ & 1,148 \\
\hline
\end{tabular}

Lastly, the best population number for 100,000 generation cannot be too small or too large because a bad solution will be obtained if population size is small and repeating solutions when population is large. Therefore, a summary can be made that the population size has to be large when the generation number is very small and the population size need not be very large for moderate generation number. Last but not least, a medium number of population is enough for a very large generation number.

\subsection{Comparison of GA with Available Methods}

As a further experiment for validating the performance of our GA algorithm, comparison have been made with the seven other evolutionary algorithms proposed by Maleki and Pourfayaz [10]. The findings from GA can be used as additional information to the study of Maleki and Pourfayaz [10]. Table 4 reveals the solution obtained from GA and seven other evolutionary algorithms.

Based on the values of TAC obtained from eight different algorithms, the best number of $\mathrm{PV}$, wind turbine and battery acquired from GA is 144,0 and 1,529, respectively with TAC of 53,031.32. The result showed a zero number of wind turbine which mean PV and battery are able to provide sufficient energy to the building. It is proven that GA performs better in minimizing the total annual cost of the hybrid renewable energy system. 
Table 4: The Best Sizing of PV, Wind Turbine and Battery Obtained from GA and Seven Other Evolutionary Algorithms

\begin{tabular}{|c|l|c|c|c|c|}
\hline $\begin{array}{c}\text { Hybrid } \\
\text { System }\end{array}$ & Algorithm & $\begin{array}{c}\text { Number } \\
\text { of PV } \\
\left(N_{P V}\right)\end{array}$ & $\begin{array}{c}\text { Number of } \\
\text { Wind } \\
\text { Turbine } \\
\left(N_{\text {Wind }}\right)\end{array}$ & $\begin{array}{c}\text { Number } \\
\text { of Battery } \\
\left(N_{\text {Batt }}\right)\end{array}$ & TAC \\
\hline \multirow{5}{*}{$\begin{array}{l}\text { PV-Wind } \\
\text { Burbine- }\end{array}$} & $\begin{array}{l}\text { Improved Particle } \\
\text { Swarm Optimization }\end{array}$ & 144 & 7 & 1,941 & $69,169.08$ \\
\cline { 2 - 6 } & $\begin{array}{l}\text { Particle Swarm } \\
\text { Optimization }\end{array}$ & 144 & 9 & 2,090 & $74,356.61$ \\
\cline { 2 - 6 } & $\begin{array}{l}\text { Ortificial Bee Swarm } \\
\text { Optimization }\end{array}$ & 148 & 5 & 1,529 & $56,281.59$ \\
\cline { 2 - 6 } & Sabu Search & 148 & 5 & 1,529 & $56,281.59$ \\
\cline { 2 - 6 } & $\begin{array}{l}\text { Improved Harmony } \\
\text { Search }\end{array}$ & 144 & 6 & 1,876 & $66,860.57$ \\
\cline { 2 - 6 } & $\begin{array}{l}\text { Improved Harmony } \\
\text { Search-based } \\
\text { Simulated Annealing }\end{array}$ & 144 & 6 & 1,635 & $59,624.13$ \\
\cline { 2 - 7 } & Genetic Algorithm & $\mathbf{1 4 4}$ & $\mathbf{0}$ & $\mathbf{1 , 5 2 9}$ & $\mathbf{5 3 , 0 3 1 . 3 2}$ \\
\hline
\end{tabular}

\section{Conclusion}

Overall, we believe that the work done in this study contributes positively to scientific research in minimizing the solution cost of a hybrid renewable energy system towards the concept of cost ZEB. Since combustion energy release some gases to the surrounding, which is not environmental friendly, many researchers had done their studies on the performance of renewable energy system in a building. Recently, some published papers reviewed an idea of ZEB with the concept of zero carbon emission and low building cost. Then, some researchers have found that the application of renewable energy can be related to the concept of ZEB [3133]. In the study of Yang et al. [20], Kaabeche et al. [21] and Maleki and Pourfayaz [10], the authors claimed that a hybrid PV-wind-battery system is able to support the energy load of a building in low investment cost. This low investment cost can be achieved by using suitable optimization method to optimize the configuration of an energy system.

There are many optimization methods, which can be used to minimize solution cost of a problem such as steepest descent method, Newton's method and Gradient search method. However, heuristic method is used in our study due to its robustness property in escaping the searching process from local optima. One of the heuristic methods, GA is efficient in minimizing cost function of a hybrid PV-wind-battery system as published by Koutroulis et al. [34], Bilal et al. [35], Kalantar [36] and Ramoji and Kumar [37].

By doing the parameter estimation, the application of GA in minimizing TAC of a hybrid PV-wind-battery system can contribute to the minimum solution cost of construction and 
environment. A low solution cost of a hybrid energy system would be the main interest of investors in constructing a new building. Besides, the optimization of GA parameters provides some useful information about the relationship of generation and population number to future study on the robustness of GA. Based on our study, the result showed that a large number of generation yields the best solution cost with medium population size. In other word, the population size is $3 \%$ of the generation number. From our study, the best population size is 3,000 when the generation number is 100,000 .

\subsection{Future Works}

This study mainly studied the application of GA in minimizing the cost function without considering the effect of energy load demand. Therefore, the obtained results of the number of PV, wind turbine and battery should be used to calculate the total energy that can be generated. Then, this generated energy is compared with the energy load demand. An optimum configuration of a hybrid energy system is not only dependent on its cost function but the total generated energy to support the energy demand of the building.

Moreover, a comparison on solution cost of a hybrid energy system with existing energy can be made to identify how renewable energy system is more cost-effective than the current energy system towards the goal of cost ZEB. Since the other objective of ZEB is zero carbon emission, this study can be further expanded to identify the carbon emission of the hybrid PV-windbattery system. This information can support the effectiveness of the hybrid energy system towards the target of ZEB. This is because, environmental issue will be the main concern in future study corresponding to global warming issue, increases of energy demand and depletion of existing energy.

\section{Acknowledgments}

This work is supported by Research Management Center, Universiti Teknologi Malaysia (UTM) under the Vot GJ130000.2626.11J90. The support is gratefully acknowledged.

\section{References}

[1] 1 Chong, C., Ni, W., Ma, L., Liu, P. and Li, Z. The use of energy in Malaysia: tracing energy flows from primary source to end use. Energies. 2015. 8(4): 2828-2866.

[2] Team, T. C. W., Pachauri, R. K. and Meyer, L. Climate change 2014: synthesis report. Contribution of Working Groups I, II and III to the Fifth Assessment Report of the Intergovernmental Panel on Climate Change. IPCC. 2014

[3] Torcellini, P., Pless, S. and Deru, M. Zero Energy Buildings: A Critical Look at the Definition. National Renewable Energy Laboratory. Pacific Grove, California: ACEEE Summer Study. 2006.

[4] Crawley, D., Pless, S. and Torcellini, P. Getting to net zero. ASHRAE Journal. 2009. 51(9): $18-25$. 
[5] Brinks, P., Kornadt, O. and Oly, R. Development of concepts for cost-optimal nearly zero-energy buildings for the industrial steel building sector. Applied Energy. 2016. 173: 343-354.

[6] Hernandez, P. and Kenny, P. From net energy to zero energy buildings: defining life cycle zero energy buildings (LC-ZEB). Energy Buildings. 2010. 42(6): 815-821.

[7] Huat, N. B. and bin Akasah, Z. A. An overview of Malaysia green technology corporation office building: A showcase energy-efficient building project in Malaysia. Journal of Sustainable Development. 2011. 4(5): 212-228.

[8] Thalfeldt, M., Kurnitski, J. and Mikola, A. Nearly zero energy office building without conventional heating. Estonian Journal of Engineering. 2013. 19(4): 309-328.

[9] Pikas, E., Thalfeldt, M. and Kurnitski, J. Cost optimal and nearly zero energy building solutions for office buildings. Energy and Buildings. 2014. 74: 30- 42.

[10] Maleki, A. and Pourfayaz, F. Optimal sizing of autonomous hybrid photovoltaic/wind/battery power system with LPSP technology by using evolutionary algorithms. Solar Energy. 2015. 115: 471-483.

[11] Tezer, T., Yaman, R. and Yaman, G. Evaluation of approaches used for optimization of stand-alone hybrid renewable energy systems. Renewable and Sustainable Energy Reviews. 2017. 73: 840-853, 2017.

[12] Anoune, K., Bouya, M., Astito, A. and Abdellah, A. B. Sizing methods and optimization techniques for PV-wind based hybrid renewable energy system: a review. Renewable and Sustainable Energy Reviews. 2018. 93: 652-673.

[13] Ogunjuyigbe, A. S. O., Ayodele, T. R. and Akinola, O. A. Optimal allocation and sizing of $\mathrm{PV} /$ Wind/Split-diesel/Battery hybrid energy system for minimizing life cycle cost, carbon emission and dump energy of remote residential building. Applied Energy. 2016. 171: 153171.

[14] Gan, L. K., Shek, J. K., and Mueller, M. A. Optimised operation of an off-grid hybrid wind-diesel-battery system using genetic algorithm. Energy Conversion and Management. 2016. 126: 446-462.

[15] Starke, A. R., Cardemil, J. M., Escobar, R. and Colle, S. Multi-objective optimization of hybrid CSP+ PV system using genetic algorithm. Energy. 2018. 147: 490-503.

[16] Pikas, E., Kurnitski, J., Liias, R. and Thalfeldt, M. Quantification of economic benefits of renovation of apartment buildings as a basis for cost optimal 2030 energy efficiency strategies. Energy and Buildings. 2015. 86: 151-160.

[17] Lu, Y., Wang, S. and Shan, K. Design optimization and optimal control of grid-connected and standalone nearly/net zero energy buildings. Applied Energy. 2015. 155: 463-477.

[18] Kolokotsa, D. E. K. D., Rovas, D., Kosmatopoulos, E. and Kalaitzakis, K. A roadmap towards intelligent net zero-and positive-energy buildings. Solar Energy. 2011. 85(12): 3067-3084.

[19] Photovoltaic System. Wikipedia the Free Encyclopedia. 2016.

[20] Yang, H., Zhou, W., Lu, L. and Fang, Z. Optimal sizing method for stand-alone hybrid solar-wind system with LPSP technology by using genetic algorithm. Solar energy. 2008. 82(4): 354-367. 
[21] Kaabeche, A., Belhamel, M. and Ibtiouen, R. Sizing optimization of grid-independent hybrid photovoltaic/wind power generation system. Energy 2011. 36(2): 1214-1222.

[22] Li, C., Ge, X., Zheng, Y., Xu, C., Ren, Y., Song, C. and Yang, C. Techno-economic feasibility study of autonomous hybrid wind/PV/battery power system for a household in Urumqi, China. Energy. 2013. 55: 263-272.

[23] Wang, R., Li, G., Ming, M., Wu, G. and Wang, L. An efficient multi-objective model and algorithm for sizing a stand-alone hybrid renewable energy system. Energy. 2017. 141: 2288-2299.

[24] Ismail, M. S., Moghavvemi, M. and Mahlia, T. M. I. Characterization of PV panel and global optimization of its model parameters using genetic algorithm. Energy Conversion and Management. 2013. 73: 10-25

[25] Askarzadeh, A. A discrete chaotic harmony search-based simulated annealing algorithm for optimum design of PV/wind hybrid system. Solar Energy. 2013. 97: 93-101

[26] Maleki, A. and Askarzadeh, A. Optimal sizing of a PV/wind/diesel system with battery storage for electrification to an off-grid remote region: A case study of Rafsanjan, Iran. Sustainable Energy Technologies and Assessments. 2014. 7: 147-153.

[27] Kapsalaki, M., Leal, V. and Santamouris, M. A methodology for economic efficient design of Net Zero Energy Buildings. Energy and Buildings. 2012 55: 765-778.

[28] Geem, Z. W. Size optimization for a hybrid photovoltaic-wind energy system. International Journal of Electrical Power and Energy Systems. 2012. 42(1): 448-451.

[29] Siam, F. M., Kamal, M. H. A. and Johar, F. Parameter estimation for a mechanistic model of high dose irradiation damage using Nelder-Mead Simplex Method and Genetic Algorithm. Jurnal Teknologi. 2016. 78(12-2): 87-92.

[30] Magalhães, C. S. D., Barbosa, H. J. and Dardenne, L. E. A genetic algorithm for the ligand-protein docking problem. Genetics and Molecular Biology. 2004. 27(4): 605-610.

[31] Good, C., Andresen, I. and Hestnes, A. G. Solar energy for net zero energy buildings: a comparison between solar thermal, PV and photovoltaic-thermal (PV/T) systems. Solar Energy. 2015. 122: 986-996.

[32] Zhang, S., Jiang, Y., Xu, W., Li, H. and Yu, Z. Operating performance in cooling mode of a ground source heat pump of a nearly-zero energy building in the cold region of China. Renewable energy. 2016. 87: 1045-1052.

[33] Good, C., Kristjansdottír, T., Wiberg, A. H., Georges, L. and Hestnes, A. G. Influence of PV technology and system design on the emission balance of a net zero emission building concept. Solar Energy. 2016. 130: 89-100.

[34] Koutroulis, E., Kolokotsa, D., Potirakis, A. and Kalaitzakis, K. Methodology for optimal sizing of stand-alone photovoltaic/wind-generator systems using genetic algorithms. Solar energy. 2006. 80(9): 1072-1088.

[35] Bilal, B. O., Sambou, V., Ndiaye, P. A., Kébé, C. M. F. and Ndongo, M. Optimal design of a hybrid solar-wind-battery system using the minimization of the annualized cost system and the minimization of the loss of power supply probability (LPSP). Renewable Energy. 2010. 35(10): 2388-2390. 
[36] Kalantar, M. Dynamic behavior of a stand-alone hybrid power generation system of wind turbine, microturbine, solar array and battery storage. Applied energy. 2010. 87(10): 30513064.

[37] Ramoji, S. K. and Kumar, B. J. Optimal economical sizing of a PV-Wind hybrid energy system using genetic algorithm and teaching learning-based optimization. International Journal of Advanced Research in Electrical, Electronics and Instrumentation Engineering. 2014. 3(2): 7352-7367. 